\title{
Temporal Changes in Breast Milk Fatty Acids Contents: A Case Study of Malay Breastfeeding Women
}

\author{
Geok Lin Khor ${ }^{1, *} \mathbb{D}$, Seok Shin Tan ${ }^{1}{ }^{(\mathbb{D}}$, Eline Stoutjesdijk ${ }^{2}$, Kock Wai Tony Ng ${ }^{1}$, Ilse Khouw ${ }^{3}$, Marjolijn Bragt ${ }^{3}$, \\ Anne Schaafsma $^{3}$, D. A. Janneke Dijck-Brouwer ${ }^{2}$ and Frits A. J. Muskiet ${ }^{2}$ \\ 1 Department of Nutrition \& Dietetics, School of Health Sciences, International Medical University, \\ 57000 Kuala Lumpur, Malaysia; seokshin83@gmail.com (S.S.T.); drtonyngkw@gmail.com (K.W.T.N.) \\ 2 Laboratory Medicine, University Medical Center Groningen and University of Groningen, \\ 9713 GZ Groningen, The Netherlands; e.stoutjesdijk@umcg.nl (E.S.); d.a.j.dijck@umcg.nl (D.A.J.D.-B.); \\ f.a.j.muskiet@umcg.nl (F.A.J.M.) \\ 3 FrieslandCampina, 3800 BN Amersfoort, The Netherlands; Ilse.Tan-Khouw@frieslandcampina.com (I.K.); \\ Marjolijn.Bragt@frieslandcampina.com (M.B.); Anne.Schaafsma@frieslandcampina.com (A.S.) \\ * Correspondence: khor.geoklin@gmail.com
}

check for updates

Citation: Khor, G.L.; Tan, S.S.; Stoutjesdijk, E.; Ng, K.W.T.; Khouw, I.; Bragt, M.; Schaafsma, A.;

Dijck-Brouwer, D.A.J.; Muskiet,

F.A.J. Temporal Changes in Breast Milk Fatty Acids Contents: A Case Study of Malay Breastfeeding

Women. Nutrients 2021, 13, 101. https://doi.org/10.3390/nu13010101

Received: 29 October 2020 Accepted: 21 December 2020 Published: 30 December 2020

Publisher's Note: MDPI stays neutral with regard to jurisdictional clai$\mathrm{ms}$ in published maps and institutional affiliations.

Copyright: (C) 2020 by the authors. Licensee MDPI, Basel, Switzerland. This article is an open access article distributed under the terms and conditions of the Creative Commons Attribution (CC BY) license (https:// creativecommons.org/licenses/by/ $4.0 /)$.

\begin{abstract}
The composition of human breast milk changes in the first two months of life, adapting itself to the evolving needs of the growing new-born. Lipids in milk are a source of energy, essential fatty acids (FA), fat-soluble vitamins, and vital bioactive components. Information on breast milk FA of Malaysian lactating women is scarce. Based on convenience sampling, a total of 20 Malay breastfeeding women who fulfilled the inclusion criteria were recruited. Breast milk was collected three times from each subject at consecutive intervals of 2-3 weeks apart. A total of 60 breast milk samples were collected and classified into "transitional milk" $(n=8)$, "early milk" $(n=26)$ and "mature milk" ( $n=26)$. All milk samples were air freighted to University of Groningen, Netherlands for analysis. The dominant breast milk FA were oleic acid, constituting 33\% of total fatty acids, followed by palmitic acid (26\%). Both these FA and the essential FA, linoleic acid (10\%) and alphalinolenic acid $(0.4 \%)$, showed no significant changes from transitional to mature milk. Breast milk ratio of n-6:n-3 polyunsaturated fatty acids (PUFA) was comparatively high, exceeding 10 throughout the lactation period, suggesting a healthier balance of PUFA intake is needed in pregnancy and at postpartum.
\end{abstract}

Keywords: breast milk fatty acids; temporal changes; maternal dietary intake; postpartum

\section{Introduction}

Fats are important constituents of human breast milk providing energy and nutrients to support the growth and development of the breast-fed infant. In general, human breast milk fat content ranges from $3.5 \%$ to $4.5 \%$ during lactation with triglycerides as the main lipid fraction, accounting for about $95 \%$ of total lipids. Approximately, half of milk fatty acids are saturated fatty acids, with palmitic acid (C16:0) making up about $23 \%$ of the total fatty acids [1]. Overall, oleic acid (C18:1 n-9) constitutes the highest percentage (about 36\%) of the total fatty acids in human milk.

The composition of human breast milk changes in the first two months of life, adapting itself to the evolving needs of the growing new-born. The first fluid that is expressed by the mother after delivery is colostrum, which has high immunologic components and low concentrations of lactose, indicating its primary functions to be immunologic rather than nutritional [2]. In this respect, Gila-Diaz et al. (2019) [3] have provided an insightful elaboration on the presence of several bioactive compounds in breast milk, which contribute to the maturation of the immune system of the breastfed infant, among other important aspects. At the beginning of lactation, milk fat also contains more capric acid (C10:0) and lauric acid (C12:0) as these are readily metabolised and are also believed to confer immunological benefits. 
As lactation proceeds, lactose concentration increases indicating secretory activation and the production of transitional milk [2]. Transitional milk, typically occurring from day 7 to day 10 postpartum to 2 weeks postpartum, contains increasingly higher concentrations of energy and nutrients to support the nutritional and developmental needs of the rapidly growing infant. By four to six weeks postpartum, human milk is considered fully mature.

As fat is recognised as a highly variable component in breastmilk, and its fatty acid composition is known to be influenced by multiple external factors including maternal diet, the relationship between breast milk fatty acids and maternal dietary intake has been extensively studied. In a systematic review of the impact of maternal nutrition on breast milk composition, which included 17 studies on dietary effects on breast milk fatty acids, Bravi et al. (2016) [4] reported several limitations in comparing the studies. These included heterogeneity in study designs and lack of control for confounding factors. In their meta-analysis of 41 studies, Gidrewicz and Fenton (2014) [5] revealed more similarities than differences between preterm and term milk for energy, fat, oligosaccharides, calcium, and phosphorus.

The exclusively breastfed infant depends on human milk for essential fatty acids namely, linoleic acid (LA) (18:2 n-6) and alpha-linolenic acid (ALA) (C18:3 n-3). Both LA and ALA serve as precursors to physiologically important polyunsaturated metabolites, including arachidonic acid (AA) (20:4 n-6), eicosapentaenoic acid (EPA) (20:5 n-3) and docosahexaenoic acid (DHA) (22:6 n-3). The role of DHA in infant nutrition is of particular importance because it is accumulated during perinatal development specifically in the membrane lipids of the brain and retina, where DHA plays vital roles in visual acuity vision and motor systems in newborns [6].

EPA and DHA are derived mainly from fish and other seafoods including seaweed [7]. Several studies world-wide have reported low amounts of EPA and DHA in maternal diets [8-10]. Low maternal intake of DHA in particular may lead to low breast milk DHA levels, which in turn place the infant at risk of dysfunction of the central nervous system, plausibly impairing cognition and vision [11].

Given the important roles of fatty acids in breast milk for infant growth and development, and in view of a lack of data on breast milk fatty acids in Malaysia, this study is aimed at generating information on fatty acids composition and maternal dietary intake among Malay lactating women. Such information is also pertinent in relation to the notable increase in the prevalence of breastfeeding among Malaysian women in recent years. The national prevalence of exclusive breastfeeding increased from $19.3 \%$ in 2006 to $47.1 \%$ in 2016 according to the National Health and Morbidity Survey (NHMS) of 2006 and 2016 [12]. The NHMS also showed that exclusive breastfeeding prevalence in urban areas has risen significantly over the same period from $12.9 \%$ to $48.3 \%$.

We have lately published a case study on the breastmilk mineral contents of Malay lactating women living in urban areas [13]. The present report follows up on the fatty acids contents of breast milk samples that were collected from the Malay lactating women.

\section{Methodology}

\subsection{Ethics Approval and Consent to Participate}

This study was undertaken in agreement with the Helsinki declaration of 1975 as revised in 2013. The International Medical University Joint Committee on Research and Ethics gave approval for this study with the approval number of IMU R123. The International Medical University Joint Committee on Research and Ethics operates in accordance with the International Conference of Harmonization/Good Clinical Practice Guidelines (ICH-GCP) Guidelines, the Declaration of Helsinki 2000, and Malaysian Good Clinical Practice. The study proposal was also registered in the Netherlands National Trial Register with the registration number of NTR 4404. 


\subsection{Study Design and Subjects}

This is a cross-sectional study conducted in an urban residential area of Kuala Lumpur, the capital city of Malaysia. The study location was purposively selected for its largely Malay residents. Malay women were selected as they are known to breastfeed longer on average than other ethnic urban populations [14]. In addition, Malay women are known to have culturally different dietary practices during pregnancy and postpartum that might affect the milk contents $[15,16]$.

\subsection{Inclusion and Exclusion Criteria}

\subsubsection{Inclusion Criteria}

1. Apparently healthy Malay women aged $20-40$ years

2. Women breastfeeding throughout the milk collection period

3. Infant born singleton, gestational age $\geq 37$ weeks, birth weight $\geq 2500 \mathrm{~g}$

\subsubsection{Exclusion Criteria}

1. Infant at recruitment older than 2 weeks to exclude colostrum milk feeding

2. Breastfeeding women on special diets

3. Breastfeeding women taking dietary supplements including fatty acid supplements

4. Breastfeeding women fasting during milk collection period

5. Breastfeeding women or child feeling sick at recruitment

\subsection{Subject Recruitment Process}

Recruitment of subjects was based on community feedback on households with breastfeeding women. The study protocol was explained to women who fulfilled the inclusion criteria. However, several did not agree to participate, giving reasons such as "too busy to commit", "husband did not agree" and "working outside the home". Through the 'snowball' approach, a total of 20 women who fulfilled the study criteria agreed to participate in the study. All gave written consent for their participation. Appointments were scheduled for three consecutive collections of breast milk samples and interviewing regarding the dietary intake of the women.

\subsection{Collection of Milk Samples}

Throughout the milk collection period, milk samples were collected in the morning to standardise the timing of collection and to minimise circadian effects on milk composition [17]. Before collecting milk sample, the nipples and areolas of the breast were cleaned with $70 \%$ alcohol ethyl alcohol. Complete milk was expressed from one breast by a trained research assistant using a manual breast pump (Phillips Avent model SCF 330-13). In this way, at least $25 \mathrm{~mL}$ breast milk from each subject was collected and transferred into a sterile tube. The milk samples collected were placed together with ice packs inside a portable insulated container and transported within 5-h of collection to the institution laboratory (IMU) for storage at minus $80^{\circ} \mathrm{C}$. Overall, breast milk was collected three times from each subject at consecutive intervals of 2-3 weeks apart. Hence a total of 60 breast milk samples were collected from the 20 subjects.

\subsection{Determination of Breast Milk Fatty Acids}

The milk samples were air freighted on dry ice to the University Medical Center Groningen (UMCG), The Netherlands for fatty acids composition analysis. They were stored at minus $20^{\circ} \mathrm{C}$ until further analysis. The breast milk samples were thawed at room temperature prior to analysis. An aliquot of $100 \mathrm{uL}$ was transferred into a Telfon-sealable tube (Sovirel), containing $2 \mathrm{~mL}$ of methanol: $6 \mathrm{~mol} / \mathrm{L} \mathrm{HCl}(5: 1, v / v), 1 \mathrm{mg}$ of butylated hydroxytoluene (antioxidant), $100 \mathrm{uL}$ of 5:0-15:0 and $50 \mathrm{uL}$ of 17:0 internal quantification standards. These ready-to-transmethylate fatty acid mixtures were trans-methylated by heating to $90{ }^{\circ} \mathrm{C}$ for 4 -h. After extraction, analysis of fatty acids methyl esters (FAME) was performed by capillary gas chromatography/ flame ionization detection using a 
series of odd-chain numbered fatty acids (5:0-17:0) as internal quantification standards. In brief, the samples were injected into gas chromatography (Hewlett Packard, Model 5880), equipped with a $25 \mathrm{~m} \times 0.25 \mathrm{~mm}$ I.D. CP-Sil-88-coated (film thickness $0.25 \mathrm{um}$ ) fused-silica column (Chrompack, Middelburg, The Netherlands). The flow rate for helium gas was set at $0.65 \mathrm{~mL} / \mathrm{min}$, split ratio of $1: 15$, temperature for flame ionization detector of $300{ }^{\circ} \mathrm{C}$ and injector temperature of $200{ }^{\circ} \mathrm{C}$. The oven temperature programme was set as $150{ }^{\circ} \mathrm{C}$, $1{ }^{\circ} \mathrm{C} / \mathrm{min}$ to $200^{\circ} \mathrm{C}, 10 \mathrm{~min}$ at $200^{\circ} \mathrm{C}[18,19]$. The composition of fatty acids in the breast milk samples was recorded as percentage of total fatty acids $(\mathrm{g} \%)$.

Based on the age of the infants when the breast milk was collected, this study categorised lactation stage according to the terminology used in Ballard and Morrow (2013) [2] and Li et al. (2016) [20]. Milk samples collected at week 2 to week 3 postpartum were labelled as "transitional" milk (T1), at week $>3$ to week 8 as "early" milk (T2), and at week $>8$ to week 16 as "mature" milk (T3). Out of the total 60 breast milk samples collected, there were 8 samples of transitional breast milk, 26 samples of early milk and 26 samples of mature milk.

\subsection{Maternal Dietary Intake Assessment}

During each milk collection, the breastfeeding women were interviewed on their dietary intake using the $24-\mathrm{h}$ recall method. In this way, a total of three $24-\mathrm{h}$ recall records of food intake were obtained from each subject at consecutive $2-3$ week intervals. The macronutrients and fatty acid contents of various food consumed by the subjects were computed using the Malaysian Food Composition [21], United States Department of Agriculture (USDA) Nutrient Database [22] and the Australia Food, Supplement and Nutrient Database (AUSNUT) [23] in the above order of priority. The results were reported as mean \pm SD for macronutrients, saturated fatty acids (SFA), monounsaturated fatty acids (MUFA) and polyunsaturated fatty acids (PUFA) and as percentage meeting the daily recommendations for Malaysia [24].

\subsection{Statistical Analysis}

Statistical analyses were conducted using the SPSS (Statistical Package for Social Sciences) version 20. Descriptive statistics were expressed as mean \pm standard deviation (SD). The breast milk fatty acid contents at different lactation stages as well as the maternal dietary intake of fatty acids at the three collection times were analysed by ANOVA and post hoc Fisher's Least Significant Differences (LSD) tests. Significance level was set at $p<0.05$ for all analyses.

\section{Results}

\subsection{Socio-Demographic Background}

The socio-demographic background of the breastfeeding women was previously described in Tan et al. (2020) [13]. Briefly, the women and their spouses had a mean age of $31.4 \pm 6.1$ and $33.8 \pm 7.4$ years, respectively. The majority of the women and their spouses had completed more than 10 years of formal schooling. While the majority of the women were housewives, their spouses were employed in the service and production industry.

The women had a mean body mass index (BMI) of $26.0 \pm 5.1 \mathrm{~kg} / \mathrm{m}^{2}$, indicating that the subjects had normal to obese BMI status. The authors considered the small sample size $(n=20)$ in this study precludes meaningful statistical determination of the association between maternal BMI and breast milk contents. While positive associations between maternal BMI and breast milk fat contents have been reported $[25,26]$, the latter has also pointed out contradictory findings.

Among the infants in the study, there were more female $(70 \%)$ than male. Data on their birth weight, ranging from $2840 \mathrm{~g}$ to $3780 \mathrm{~g}$, indicates that none of the infants were born with low birth weight. 


\subsection{Breast Milk Fatty Acid Concentrations}

Oleic acid (C18:1 n-9) is the predominant fatty acid in the breast milk constituting about $33 \%$ of the total fatty acids at each of the three stages of lactation (T1, T2 \& T3) (Table 1). The next highest level is palmitic acid (C16:0) forming about $26 \%$ followed by linoleic acid (C18:2 n-6) (approximately 10\%) and lauric acid (C12:0) (about 9\%). These relative proportions of the breast milk fatty acids do not change significantly as lactation progresses from the transitional milk to mature milk stage.

Table 1. Breast milk fatty acids concentrations according to the stage of lactation (T1, T2 \& T3).

\begin{tabular}{|c|c|c|c|}
\hline \multirow[b]{2}{*}{$\begin{array}{c}\text { Breast Milk Fatty Acids Contents } \\
\% \text { of Total Fatty Acids }\end{array}$} & \multicolumn{3}{|c|}{ Stage of Lactation } \\
\hline & $\begin{array}{c}\text { Transitional Milk (T1) } \\
\text { 2-3 Weeks } \\
(n=8)\end{array}$ & $\begin{array}{c}\text { Early Milk (T2) } \\
>3-8 \text { Weeks } \\
(n=26)\end{array}$ & $\begin{array}{c}\text { Mature Milk (T3) } \\
>8-16 \text { Weeks } \\
(n=26)\end{array}$ \\
\hline & & Mean \pm SD & \\
\hline 6:0 (Caproic acid) & $0.11 \pm 0.02$ & $0.12 \pm 0.01$ & $0.13 \pm 0.01$ \\
\hline 8:0 (Caprylic acid) & $0.42 \pm 0.03$ & $0.45 \pm 0.03$ & $0.42 \pm 0.02$ \\
\hline 10:0 (Capric acid) & $2.29 \pm 0.23$ & $2.13 \pm 0.15$ & $2.09 \pm 0.07$ \\
\hline 12:0 (Lauric acid) & $9.61 \pm 0.84^{\mathrm{a}}$ & $8.14 \pm 0.77^{b}$ & $8.96 \pm 0.46^{\mathrm{a}, \mathrm{b}}$ \\
\hline 14:0 (Myristic acid) & $7.22 \pm 0.55^{\mathrm{a}}$ & $6.20 \pm 0.55^{b}$ & $7.42 \pm 0.41^{\mathrm{a}}$ \\
\hline 14:1 n-5 (Myristoleic acid) & $0.04 \pm 0.01^{\mathrm{a}}$ & $0.13 \pm 0.01^{b}$ & $0.09 \pm 0.01^{\mathrm{a}, \mathrm{b}}$ \\
\hline 16:0 (Palmitic acid) & $25.2 \pm 1.25^{\mathrm{a}}$ & $26.3 \pm 0.35^{b}$ & $26.8 \pm 0.47^{b}$ \\
\hline 16:1 n-7 (Palmitoleic acid) & $3.09 \pm 0.38$ & $3.26 \pm 0.19$ & $2.61 \pm 0.17$ \\
\hline 18:0 (Stearic acid) & $4.26 \pm 0.04$ & $4.81 \pm 0.14$ & $4.70 \pm 0.13$ \\
\hline 18:1 n-7 (Vaccenic acid) & $1.58 \pm 0.26$ & $1.85 \pm 0.06$ & $1.53 \pm 0.09$ \\
\hline 18:1 n-9 (Oleic acid) & $33.0 \pm 1.11^{\mathrm{a}, \mathrm{b}}$ & $33.7 \pm 0.81^{\mathrm{a}}$ & $32.5 \pm 0.47^{b}$ \\
\hline 18:2 n-6 (Linoleic acid) & $10.1 \pm 0.60$ & $10.1 \pm 0.32$ & $9.83 \pm 0.26$ \\
\hline $18: 3 n-3(\alpha$-Linolenic acid $)$ & $0.44 \pm 0.2$ & $0.35 \pm 0.02$ & $0.32 \pm 0.03$ \\
\hline $18: 3 n-6(\gamma$-Linolenic acid $)$ & $0.09 \pm 0.02$ & $0.09 \pm 0.01$ & $0.08 \pm 0.01$ \\
\hline 20:0 (Arachidic acid) & $0.14 \pm 0.01$ & $0.15 \pm 0.01$ & $0.16 \pm 0.01$ \\
\hline $20: 1$ n-9 (Eicosenoic acid) & $0.31 \pm 0.04$ & $0.30 \pm 0.01$ & $0.29 \pm 0.02$ \\
\hline $20: 2$ n-6 (Eicosadienoic acid) & $0.20 \pm 0.01$ & $0.20 \pm 0.01$ & $0.19 \pm 0.02$ \\
\hline 20:3 n-6 (Dihomo-linolenic acid) & $0.33 \pm 0.04$ & $0.31 \pm 0.02$ & $0.30 \pm 0.02$ \\
\hline 20:4 n-6 (Arachidonic acid) (ARA) & $0.43 \pm 0.04$ & $0.38 \pm 0.02$ & $0.37 \pm 0.02$ \\
\hline 20:5 n-3 (Eicosapentaenoic acid) (EPA) & $0.05 \pm 0.01$ & $0.06 \pm 0.01$ & $0.07 \pm 0.01$ \\
\hline 22:0 (Behenic acid) & $0.07 \pm 0.01$ & $0.07 \pm 0.01$ & $0.08 \pm 0.01$ \\
\hline 22:4 n-6 (Docosatetraenoic acid) & $0.10 \pm 0.01$ & $0.08 \pm 0.01$ & $0.08 \pm 0.01$ \\
\hline 22:5 n-3 (Docosapentaenoic acid) & $0.11 \pm 0.01$ & $0.11 \pm 0.01$ & $0.13 \pm 0.01$ \\
\hline 22:5 n-6 (Docosapentaenoic acid) & $0.01 \pm 0.01$ & $0.06 \pm 0.01$ & $0.07 \pm 0.01$ \\
\hline 22:6 n-3 (Docosahexaenoic acid) (DHA) & $0.45 \pm 0.06$ & $0.47 \pm 0.05$ & $0.56 \pm 0.05$ \\
\hline 24:0 (Lignoceric acid) & $0.07 \pm 0.01$ & $0.07 \pm 0.01$ & $0.08 \pm 0.01$ \\
\hline 24:1 n-9 (Nervonic acid) & $0.07 \pm 0.01$ & $0.07 \pm 0.01$ & $0.07 \pm 0.01$ \\
\hline Sum SFA & $49.4 \pm 1.55^{\mathrm{a}}$ & $48.5 \pm 1.20^{\mathrm{a}}$ & $50.8 \pm 0.78^{b}$ \\
\hline Sum MUFA & $38.2 \pm 1.13^{a}$ & $39.3 \pm 0.95^{\mathrm{a}}$ & $37.1 \pm 0.61^{b}$ \\
\hline Sum PUFA & $12.4 \pm 0.79$ & $12.2 \pm 0.32$ & $12.0 \pm 0.34$ \\
\hline Sum n-3 & $1.06 \pm 0.16$ & $0.99 \pm 0.06$ & $1.09 \pm 0.08$ \\
\hline Sum $n-5$ & $0.04 \pm 0.01^{\mathrm{a}}$ & $0.13 \pm 0.01^{b}$ & $0.09 \pm 0.01^{\mathrm{a}, \mathrm{b}}$ \\
\hline Sum n-6 & $11.3 \pm 0.65$ & $11.2 \pm 0.33$ & $10.9 \pm 0.29$ \\
\hline Sum $n-7$ & $4.71 \pm 0.47^{\mathrm{a}, \mathrm{b}}$ & $5.11 \pm 0.24^{\mathrm{a}}$ & $4.16 \pm 0.24^{b}$ \\
\hline Sum n-9 & $33.5 \pm 1.14^{\mathrm{a}, \mathrm{b}}$ & $34.1 \pm 0.82^{a}$ & $32.9 \pm 0.48^{b}$ \\
\hline$n-6$ to $n-3$ ratio & $10.7 \pm 3.92$ & $11.3 \pm 5.79$ & $10.1 \pm 3.77$ \\
\hline ARA to DHA ratio & $0.96 \pm 0.66^{\mathrm{a}}$ & $0.80 \pm 0.34^{a}$ & $0.66 \pm 0.41^{b}$ \\
\hline
\end{tabular}

Mean values in the same row with different alphabets indicate significant difference $(p<0.05)$ based on ANOVA and post hoc LSD tests. Saturated Fatty Acids (SFA): 6:0 (Caproic acid), 8:0 (Caprylic acid), 10:0 (Capric acid), 12:0 (Lauric acid), 14:0 (Myristic acid), 16:0 (Palmitic acid), 18:0 (Stearic acid), 20:0 (Arachidic acid), 22:0 (Behenic acid), 24:0 (Lignoceric acid). Monounsaturated Fatty Acids (MUFA): 14:1 n-5 (Myristoleic acid), 16:1 n-7 (Palmitoleic acid), 18:1 n-7 (Vaccenic acid), 18:1 n-9 (Oleic acid), 20:1 n-9 (Eicosenoic acid), 24:1 n-9 (Nervonic acid). Polyunsaturated Fatty Acids (PUFA): 18:2 n-6 (Linoleic acid), 18:3 n-3 ( $\alpha$-Linolenic acid), 18:3 n-6 ( $\gamma$-Linolenic acid), 20:2 n-6 (Eicosadienoic acid), 20:3 n-6 (Dihomo-linolenic acid), 20:4 n-6 (Arachidonic acid), 20:5 n-3 (Eicosapentaenoic acid), 22:4 n-6 (Docosatetraenoic acid), 22:5 n-3 (Docosapentaenoic acid), 22:5 n-6 (Docosapentaenoic acid), 22:6 n-3 (Docosahexaenoic acid). 
It is also noted that the concentrations of the essential fatty acids, i.e., linoleic acid (18:2 n-6) and alpha-linolenic acid (18:3 n-3), which formed about $10 \%$ and $0.4 \%$ respectively of the total fatty acids, showed no significant changes across the lactation stages.

The total concentration of saturated fatty acids (SFA) increases somewhat from $49.4 \pm 1.55 \%$ in the transitional milk to $50.8 \pm 0.78 \%$ in mature milk (Table 1$)$. The dominant SFA is palmitic acid (C16:0) followed by lauric acid (C12:0), myristic acid (C14:0) and stearic acid (C18:0). Meanwhile, the sum of monounsaturated fatty acids (MUFA) decreases significantly from $38.2 \pm 1.13 \%$ to $37.1 \pm 0.61 \%$ as lactation progresses. Total polyunsaturated fatty acids (PUFA) concentration remains almost constant at about $12 \%$ throughout the lactation stages. Out of the total PUFA content, n-3 PUFA constitutes only about $1 \%$ of the total fatty acids across the stages of lactation. The n-3 PUFA in breast milk are $\alpha$-linolenic acid (C18:3), eicosapentaenoic acid (EPA) (C20:5) and docosahexaenoic acid (DHA) (C22:6). In contrast, the sum of n-6 PUFA forms about $11 \%$ of the total PUFA, resulting in the breast milk ratio of n-6 to n-3 PUFA in this study at approximately 10 to 11 through the lactation period.

\subsection{Maternal Dietary Intake}

Dietary intake of the breastfeeding women is shown according to the three-time stages of lactation, (T1, T2 and T3). Maternal intake is also shown as percentage of meeting Malaysia's daily recommended intake (RNI) for energy, macronutrients, SFA, MUFA and PUFA [24]. Overall, the average daily intake of total energy and protein of the breastfeeding women exceeded the respective RNI recommendation of 2400 kilocalories and $71 \mathrm{~g}$ (Table 2). The mean daily energy intake increased significantly from $2270.9 \pm 1004.8$ kcals at the transitional milk stage (T1) to $2435.9 \pm 806.1 \mathrm{kcals}$ at mature milk stage (T3). Likewise, the daily intake of protein increased significantly from $83.6 \pm 37.9 \mathrm{~g}$ at T1 to $94.3 \pm 39.7 \mathrm{~g}$ at T3. While rice and noodles constituted the primary sources of calories among the women postpartum, their chief protein sources were meat (beef, chicken), fish especially "ikan kembong" (Rastrelliger kanagurta), milk, eggs and soybean products (soya milk, soya curd).

In general, the total fat intake of the breastfeeding women approaches $90.3-108.0 \%$ of the Malaysian RNI level for moderately active lactating women. This intake level did not change significantly across the lactation stages. Out of the total fat intake, the mean intake of SFA of $26.7 \mathrm{~g}$ per day was about $60 \%$ of the RNI level for SFA. As a percentage of total fatty acids, the intake of SFA showed a significant declining trend from $25.1 \%$ at T1 to $21.5 \%$ at T3. In general, postpartum maternal intake levels of MUFA and PUFA were below the RNI levels, at respectively $36.5-45.6 \%$ and $45.2-70.2 \%$ across the three stages of lactation.

The main sources of fat consumed by the breastfeeding women were cooking oil, coconut cream ("santan"), fish and meat. Out of these, meat, palm oil and coconut cream constituted the major sources of SFA. Palm oil is a popular cooking oil in Malaysia, containing approximately 50\% SFA, with $44 \%$ palmitic acid (C16:0). Palm oil is also a dietary source of unsaturated fatty acids, as it comprises $40 \%$ oleic acid (C18:1n-9) and 10\% linoleic acid $(\mathrm{C} 18: 2 \mathrm{n}-6)$ and linolenic acid $(\mathrm{C} 18: 3 \mathrm{n}-3)$ [27]. Aside from palm oil, other popular types of cooking oil in Malaysia include sunflower oil, soybean oil, peanut oil, corn oil and mixed blend of vegetable oils. These oils contribute to n-6 PUFA intake of the lactating women. Intake of n-3 PUFA is likely to be derived from a wide variety of fish that the women reported consuming, including mackerel, sardine, tuna, red snapper, anchovy, pomfret and catfish. 
Table 2. Maternal dietary intake at three consecutive assessments $(\mathrm{T} 1, \mathrm{~T} 2, \mathrm{~T} 3)(\mathrm{Mean} \pm \mathrm{SD})$ and \% meeting daily recommendation $\left({ }^{*} \mathrm{RNI}\right)$.

\begin{tabular}{|c|c|c|c|c|c|c|c|c|c|}
\hline \multirow{2}{*}{ Maternal Intake } & \multicolumn{2}{|c|}{$\mathrm{T} 1(n=20)$} & \multicolumn{2}{|c|}{ T2 $(n=20)$} & \multicolumn{2}{|c|}{$\mathrm{T} 3(n=20)$} & \multicolumn{2}{|c|}{ Overall $(n=20)$} & \multirow[t]{2}{*}{$\begin{array}{l}* \text { RNI for } \\
\text { Lactation }\end{array}$} \\
\hline & (Mean \pm SD) & \%RNI & (Mean \pm SD) & \%RNI & $($ Mean \pm SD) & \%RNI & (Mean \pm SD) & \%RNI & \\
\hline Energy (kcal/day) & $2270.9 \pm 1004.8^{a}$ & $94.6 \pm 41.9$ & $2535.4 \pm 983.1^{b}$ & $105.6 \pm 41.0$ & $2435.9 \pm 806.1^{b}$ & $101.5 \pm 33.6$ & $2414.1 \pm 931.3$ & $100.6 \pm 38.8$ & 2400.0 \\
\hline $\begin{array}{c}\text { Carbohydrate } \\
\text { (g/day) }\end{array}$ & $338.2 \pm 151.6^{a}$ & $\begin{array}{c}86.7-112.7 \pm \\
38.9-50.5\end{array}$ & $368.2 \pm 164.3^{b}$ & $\begin{array}{c}94.4-122.7 \pm \\
42.1-54.8\end{array}$ & $340.5 \pm 127.8^{\mathrm{a}}$ & $\begin{array}{c}87.3-113.5 \pm \\
32.8-42.6\end{array}$ & $348.9 \pm 147.8$ & $\begin{array}{c}89.5-116.3 \pm \\
37.9-49.3\end{array}$ & $300.0-390.0$ \\
\hline Protein (g/day) & $83.6 \pm 37.9^{a}$ & $117.7 \pm 53.4$ & $100.8 \pm 59.9^{b}$ & $141.9 \pm 84.4$ & $94.3 \pm 39.7^{b}$ & $132.8 \pm 55.9$ & $92.9 \pm 45.8$ & $130.8 \pm 64.5$ & 71.0 \\
\hline $\begin{array}{c}\text { Cholesterol } \\
\text { (mg/day) }\end{array}$ & $163.2 \pm 123.6^{\mathrm{a}}$ & $54.4 \pm 41.2$ & $412.7 \pm 660.7^{b}$ & $137.6 \pm 220.2$ & $285.2 \pm 195.6^{c}$ & $95.1 \pm 65.2$ & $287.1 \pm 326.6$ & $95.7 \pm 108.9$ & 300 \\
\hline \multicolumn{10}{|l|}{$\begin{array}{c}\text { Sum of } \\
\text { Fatty Acids }\end{array}$} \\
\hline SFA (g) & $16.2 \pm 11.9$ & $60.7 \pm 44.6$ & $17.3 \pm 10.9$ & $64.8 \pm 40.8$ & $16.6 \pm 11.1$ & $62.2 \pm 41.6$ & $16.7 \pm 11.3$ & $62.5 \pm 42.3$ & 26.7 \\
\hline MUFA (g) & $12.6 \pm 8.0^{a}$ & $\begin{array}{c}31.5-39.4 \pm \\
20.0-25.0\end{array}$ & $16.2 \pm 10.2^{b}$ & $\begin{array}{c}40.5-50.6 \pm \\
25.5-31.9\end{array}$ & $15.0 \pm 9.3^{b}$ & $\begin{array}{c}37.5-46.9 \pm \\
23.3-29.1\end{array}$ & $14.6 \pm 9.2$ & $\begin{array}{c}36.5-45.6 \pm \\
23.0-28.8\end{array}$ & $32.0-40.0$ \\
\hline PUFA (g) & $8.1 \pm 7.1^{a}$ & $\begin{array}{c}37.0-57.4 \pm \\
32.4-50.4\end{array}$ & $11.2 \pm 6.7^{b}$ & $\begin{array}{c}51.1-79.4 \pm \\
30.6-47.5\end{array}$ & $10.3 \pm 6.5^{b}$ & $\begin{array}{c}47.0-73.0 \pm \\
29.7-46.1\end{array}$ & $9.9 \pm 6.8$ & $\begin{array}{c}45.2-70.2 \pm \\
31.1-48.2\end{array}$ & $14.1-21.9$ \\
\hline SFA $(\%)$ & $25.1^{\mathrm{a}}$ & & $24.0^{\mathrm{a}}$ & & $21.5^{b}$ & & 23.4 & & \\
\hline MUFA (\%) & $19.5^{\mathrm{a}}$ & & $22.4^{\mathrm{b}}$ & & $19.5^{\mathrm{a}}$ & & 20.5 & & \\
\hline PUFA (\%) & $12.5^{\mathrm{a}}$ & & $15.5^{b}$ & & $13.4^{\mathrm{a}, \mathrm{b}}$ & & 13.9 & & \\
\hline
\end{tabular}

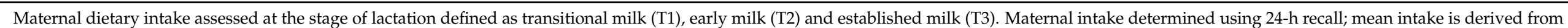

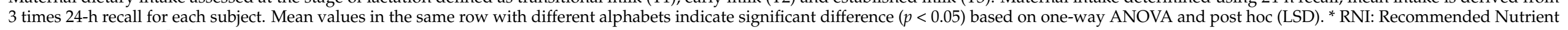
Intakes for Malaysia [24] 
Vegetables were consumed daily whereas legumes and nuts were taken on a weekly basis. Green leafy vegetables that were popular among the breastfeeding women include "sawi" (mustard; Brassica sp), "kangkong" (Ipomoea aquatica) and spinach (Amaranthaceae), as the women believed that taking vegetables such as mustard and kangkong frequently would increase production of breast milk. In general, the daily intake of the breastfeeding women showed wide inter-subject variations at each point of assessment, as indicated by the standard deviation range for the mean values.

\section{Discussion}

Human milk has been traditionally recommended as the ideal source of energy, nutrients and bioactive components to support the healthy growth and development of infants [28,29]. As fat is the most variable component in breastmilk and its composition is known to vary with external factors including maternal diet, the relationship between breast milk fatty acids and maternal dietary intake has been extensively studied. In a review of 14 studies from 9 European countries and 10 studies from 7 African countries on fatty acids in mature human milk, Koletzko et al. (1992) [30] reported that "diets in different geographic locations seem to have little effect on the milk content of 20 and 22 carbon long-chain polyunsaturated fatty acids (LCP), with the exception of relatively high n-3 fatty acids in the milk of African women consuming a large proportion of dietary fat from sea fish". The authors concluded that "the milk secretion of n-6 LCP does not appear to depend on maternal dietary intake of preformed LCP. Metabolic processes appear to be important in regulating human milk LCP". A somewhat similar finding was concluded by Yuhas et al. (2006) [31], who, in examining breast milk fatty acids of women from Asia, Australia and several western countries, stated that "the proportion of saturated and monounsaturated FA are relatively constant across a large number of countries, whereas the level of some of the PUFA, especially DHA, are highly variable". In an analysis of pooled data from 55 countries world-wide, Floris et al. (2020) [32] showed that a number of saturated fatty acids, chief of which were palmitic acid and the essential fatty acids, remain relatively stable throughout the lactation stages from colostrum to mature milk. The authors also reported that "almost all n-6 PUFA, including AA and DHA decrease steadily over the lactational stages, while the n-3 PUFA including ALA and EPA were relatively stable at all time points".

Against the background of those reviews, we compared the major fatty acids contents in the mature milk of this study with those reported by other countries (Table 3). For total saturated fatty acids (SFA), the highest level is in the breast milk from Malaysia at $49.1 \%$ (of total fatty acids) followed by Switzerland, South Korea, Poland and Canada, each within approximately $40-44 \%$. This seemingly narrow range of total SFA in mature breast milk from diverse Asian and European countries confirmed the reviews of others that the proportion of breast milk SFA is relatively constant across different populations. Another common characteristic about milk SFA of different countries is the predominance of palmitic acid (C16:0), which constitutes approximately half of the total SFA content in each country. A known unique feature of breast milk SFA is that a major proportion (70\%) of the palmitic acid is esterified in the middle position (sn-2 position) of triacylglycerols. This facilitates pancreatic lipolysis yielding a palmitoyl-monoglycerol, that is water soluble and well absorbed, hence enabling efficient digestion and absorption of C16:0 and calcium [29,33]. 
Table 3. Comparison of fatty acids contents ( $\%$ of total fatty acids) in mature breast milk ( $>2$ weeks and $\leq 16$ weeks postpartum) from selected countries.

\begin{tabular}{|c|c|c|c|c|c|c|c|c|}
\hline & $\begin{array}{l}\text { Malaysia Mean } \\
\pm \text { SD }\end{array}$ & $\begin{array}{l}\text { China Mean } \\
\quad \pm \text { SD }\end{array}$ & $\begin{array}{c}\text { South Korea Mean } \\
\pm \text { SD }\end{array}$ & Canada Mean \pm SD & $\begin{array}{l}\text { Switzerland } \\
\text { Median (IQR) }\end{array}$ & Poland Mean \pm SD & $\begin{array}{l}{ }^{*} \text { Bolivia Mean } \pm \\
\text { SD/Median (IQR) }\end{array}$ & $\begin{array}{c}{ }^{*} \text { USA Mean } \pm \\
\text { SD/Median (IQR) }\end{array}$ \\
\hline C14:0 myristic acid & $7.42 \pm 0.41$ & $4.2 \pm 1.7$ & & $5.97 \pm 1.80$ & $6.27(1.93)$ & $9.5 \pm 2.5$ & $9.81 \pm 4.18$ & $8.67 \pm 2.81$ \\
\hline C16:0 palmitic acid & $26.8 \pm 0.47$ & $19.8 \pm 2.6$ & & $20.90 \pm 2.76$ & $23.29(3.31)$ & $19.7 \pm 2.5$ & $24.96 \pm 3.13$ & $20.00 \pm 2.64$ \\
\hline C18:0 stearic acid & $4.70 \pm 0.13$ & $5.1 \pm 1.1$ & & $6.54 \pm 1.31$ & $6.75(1.69)$ & $6.4 \pm 1.5$ & $5.54 \pm 1.49$ & $6.67 \pm 1.51$ \\
\hline Total SFA & $49.1 \pm 4.9$ & $36.2 \pm 4.7$ & $42.1 \pm 5.6$ & $39.75 \pm 5.00$ & $43.86(5.93)$ & $41.9 \pm 4.9$ & & \\
\hline Oleic Acid C18:1 n-9 & $32.5 \pm 0.47$ & $31.9 \pm 3.6$ & & $37.05 \pm 3.59$ & $37.67(4.82)$ & $35.4 \pm 3.1$ & & \\
\hline Total MUFA & $38.5 \pm 3.8$ & $36.9 \pm 4.1$ & $36.3 \pm 4.9$ & $43.06 \pm 3.59$ & $43.84(4.96)$ & $39.6 \pm 3.1$ & & \\
\hline Total PUFA & $12.3 \pm 1.8$ & & $21.5 \pm 4.7$ & & $11.77(3.43)$ & $15.1 \pm 3.4$ & & \\
\hline Total n-3 PUFA & $1.05 \pm 0.10$ & $1.9 \pm 0.9$ & $3.01 \pm 1.3$ & $2.39 \pm 0.70$ & $1.11(0.36)$ & $2.7 \pm 0.9$ & 3.44 & 2.00 \\
\hline$\alpha$-Linolenic Acid C18:3 & $0.37 \pm 0.08$ & $1.5 \pm 0.9$ & & $1.92 \pm 0.61$ & $0.74(0.30)$ & $1.5 \pm 0.6$ & $1.64(0.60-2.68)$ & $1.39(0.61-2.17)$ \\
\hline EPA C $20: 5$ & $0.06 \pm 0.01$ & $0.05 \pm 0.07$ & $0.15 \pm 0.12$ & $0.08 \pm 0.05$ & $0.06(0.04)$ & $0.2 \pm 0.1$ & $1.17(0.04-0.30)$ & $0.06(0.02-0.10)$ \\
\hline DHA C22:6 & $0.49 \pm 0.05$ & $0.5 \pm 0.2$ & $0.67 \pm 0.47$ & $0.18 \pm 0.12$ & $0.28(0.17)$ & $0.7 \pm 0.3$ & $0.62(0.31-0.93)$ & $0.13(0.04-0.21)$ \\
\hline Total n-6 PUFA & $11.2 \pm 0.42$ & $24.1 \pm 5.0$ & $18.2 \pm 3.9$ & $14.80 \pm 3.09$ & $10.61(3.17)$ & $12.1 \pm 2.7$ & 12.47 & 20.58 \\
\hline Linoleic Acid C18:2 & $10.0 \pm 0.40$ & $22.8 \pm 4.9$ & & $13.62 \pm 3.01$ & $9.35(2.90)$ & $11.1 \pm 2.6$ & $9.31(3.86-14.8)$ & $18.1(12.8-24.1)$ \\
\hline $\begin{array}{c}\text { Arachidonic Acid } \\
\text { C20:4 }\end{array}$ & $0.39 \pm 30.03$ & $0.7 \pm 0.2$ & $0.48 \pm 0.13$ & $0.38 \pm 0.09$ & $0.20(0.04)$ & $0.5 \pm 0.1$ & $0.96(0.44-1.48)$ & $0.56(0.43-0.69)$ \\
\hline$n-6-n-3$ ratio & $10.1 \pm 3.77$ & $12.5 \pm 5.5$ & $6.7 \pm 2.0$ & $6.53 \pm 1.72$ & $9.58(3.31)$ & $4.6 \pm 1.0$ & 3.48 & 7.56 \\
\hline
\end{tabular}

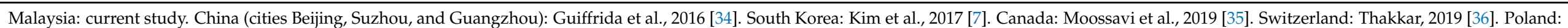
Bzikowska-Jura et al., 2019 [26]. * Bolivia and * USA: Innis, 2014 [6]; * Bolivia and * USA: Martin et al., 2012 [37]. 
To account for the exceptional SFA features in human milk, German and Dillard (2010) [38] expounded that, in the context of evolution, milk SFA has developed through natural selection to support growth and survival of mammalian offspring. These biological roles include having the short-chain SFA, butyric acid (C4:0) being preferentially hydrolysed and absorbed, thus serving as a ready source of energy, while caproic acid (C6:0) to capric acid (C10:0) are shown to exhibit antimicrobial activities. The significant presence of the triacylglycerol backbone structure of milk palmitic acid at the sn-2 position is suggested to have a positive impact on lipoprotein metabolism in infants [39], and also to impart benefits for neonatal intestinal and immunological health outcomes [40].

Similar to the fact that total SFA content is rather constant in mature breast milk from different populations, total MUFA is also reported to occur within a narrow range of concentrations in mature milk $[29,31]$. Among the Asian and European countries under consideration here (Table 3), total MUFA content lies between 36-44\%, with the Malaysian case at $39 \%$. Oleic acid (18:1 n-9) is the most abundant MUFA among the different populations, similar to other findings world-wide. While oleic acid has been shown to possess an immunomodulatory function, its role in immune responses remains inconclusive [40].

The total n-6 PUFA content in breast milk ranks highest in China (24.1\%) followed by Malaysia (11.2\%) (Table 3). Linoleic acid is the predominant $n-6$ fatty acid in all countries followed distantly by arachidonic acid (C20:4 n-6) e.g., 10\% and 0.39\% respectively in the case of Malaysia. The dominant dietary source for the high breast milk n-6 PUFA for China is cooking oils, chiefly soybean oil and peanut oil [9], whilst that for Malaysia is attributed to palm oil due primarily to its availability, affordability and good frying quality.

As for the total n-3 PUFA content, it constitutes a relatively small percentage of the overall total fatty acids in breast milk, e.g., ranging from 1.05\% for Malaysia to 3.44\% for Bolivia. The main n-3 fatty acids are $\alpha$-linolenic acid (C18:3 n-3) and DHA (C22:6 n-3) followed by EPA (C20:5 n-3). The amount of DHA in breast milk ranges from $0.18 \%$ (Canada) to $0.7 \%$ (Poland), with $0.49 \%$ for Malaysia. The DHA concentration for Malaysia appears adequate for breast fed infants based on the proposition of Koletzko (2016) [29], that "breastfeeding women need to achieve a daily DHA intake of at least $200 \mathrm{mg}$ to provide milk with a DHA content of at least $0.3 \%$, which is required for a fully breastfed infant to obtain the daily supply of about $100 \mathrm{mg}$ DHA/day considered desirable to meet metabolic needs".

The dietary source of DHA of the Malay lactating women is likely to be meat and fish. During the confinement period of about 30-60 days after delivery, Malay mothers are encouraged to consume more meat and fish as they are considered "hot" foods, which "can restore the internal heat lost from the body during delivery" [15]. The women are also encouraged to consume fish frequently postpartum, as it is a cultural belief that eating fish after delivery promotes milk flow. In this study, a wide variety of fish including anchovy, sardine and mackerel were reportedly consumed by the breastfeeding women.

In comparing the average n-6:n-3 PUFA ratio, China and Malaysia showed a comparatively high ratio of 12.5 and 10.1 respectively, while the ratio values for South Korea (6.7), Canada (6.5) and United States (7.6) were closer to the mean ratio of $6.53 \pm 1.72$ reported for 55 countries world-wide [32]. In a large multi-ethnic CHILD (Canadian Healthy Infant Longitudinal Development) cohort in Canada, Moossavi et al. (2019) [35] showed that mothers who consumed fatty cold water fish or took fish oil supplements during pregnancy and/or lactation had higher proportions of n-3 PUFAs and lower ratios of total n-6:n-3 PUFAs. The case of the relatively low n-6:n-3 ratio of 3.48 for Bolivia is explained by their subsistence on a plant-based diet with little intake of dietary energy from processed foods [37].

\section{Strengths and Limitations of Study}

To the best of our knowledge, this is the only study that provides information on the changes in the composition of breast milk fatty acids of Malay breastfeeding women, from 
postpartum week 2-3 (translational milk stage), to week 3-8 (early milk) and to week 8-16 (mature milk). Maternal dietary intake was also assessed using the 24-h recall method at each of the three lactation stages when breast milk was collected. Nonetheless, owing to the small sample size and low statistical power, we did not determine the correlations between maternal intake and breast milk fatty acids content. Overall, the maternal intake data provided insightful quantitative and descriptive perspectives on the postpartum dietary intake practices of Malay breastfeeding women. A strength of this study is that the breast milk fatty acids concentrations were determined at the Laboratory Medicine of the University Medical Center Groningen and University of Groningen, the Netherlands, which adheres to internal and external quality assessment.

\section{Conclusions}

This study has provided some useful insights into the temporal changes of breast milk fatty acids of Malay breastfeeding women. The predominant breast milk fatty acids are oleic acid (C18:1 n-9) constituting about 33\% of the total fatty acids, followed by palmitic acid (C16:0) (about 26\%). Both these fatty acids did not change significantly in concentrations in the transitional milk through the early milk and in the mature milk. Likewise, the concentrations of the essential fatty acids namely, linoleic acid (18:2 n-6) (10\%) and alpha-linolenic acid (18:3 n-3) (0.4\%), showed no significant change throughout the lactation stages. Total polyunsaturated fatty acids (PUFA) concentration remains almost constant at about $12 \%$ as lactation progresses. Out of the total PUFA, n-3 PUFA constitutes only about $1 \%$ of the total fatty acids throughout lactation. The breast milk ratio of n- 6 to n-3 PUFA of 10-11 during the lactation period is relatively high compared to the global mean ratio of approximately 6-7. In view of the physiological importance of n3 PUFA for infant growth and development, this finding indicates the need for advocating a healthier balance of PUFA intake in pregnancy and at postpartum among Malaysian women.

The above results should be verified in a larger sample size, taking into consideration that the fatty acid composition of breast milk is influenced by a myriad of factors, including current and long-term maternal diet, maternal nutritional status, diurnal variations in fatty acid synthesis, and variations between collection methods within lactation stage [41]. Also, in view of the growing prevalence of childhood obesity in Malaysia and increasing prevalence of exclusive breastfeeding practice, it is suggested that future breast milk composition studies include investigating the roles of bioactive components in breast milk [42].

Author Contributions: G.L.K., I.K. and M.B. conceptualised the study, while G.L.K., S.S.T. and K.W.T.N. designed the study and coordinated collection of data and breast milk samples. E.S., D.A.J.D.-B. and F.A.J.M. were responsible for the technical analyses of breast milk. The manuscript draft was written by G.L.K. with the cooperation of S.S.T. and A.S. All authors approved the final manuscript and agreed to be accountable for all aspects of the work. All authors have read and agreed to the published version of the manuscript.

Funding: This study was financially supported by FrieslandCampina International B.V., Leeuwarden, The Netherlands. The generous support of International Medical University Malaysia is much appreciated. The funders had no role in designing the study and interpreting the results.

Informed Consent Statement: Informed consent was obtained from all subjects involved in the study. Data Availability Statement: The data presented in this study are available within the article.

Acknowledgments: The authors are greatly appreciative of the dedication of Noor Khalijah Mohd Khalil as the project field research assistant. Our gratitude is also expressed to all the laboratory assistants at the European Laboratory of Nutrients (ELN) for the analysis of the breast milk samples. The patient cooperation of the subjects throughout the study is gratefully acknowledged.

Conflicts of Interest: The authors declare that they have no conflict of interest.

\section{References}

1. Guo, M. Human Milk Biochemistry and Infant Formula: Manufacturing Technology; Elsevier: Cambridge, UK, 2014. 
2. Ballard, O.; Morrow, A.L. Human Milk Composition. Pediatr. Clin. N. Am. 2013, 60, 49-74. [CrossRef] [PubMed]

3. Gila-Díaz, A.; Arribas, S.M.; Algara, A.; Martin-Cabrejas, M.A.; De Pablo, Á.L.; De Pipaón, M.S.; Ramiro-Cortijo, D. A Review of Bioactive Factors in Human Breastmilk: A Focus on Prematurity. Nutrients 2019, 11, 1307. [CrossRef]

4. Bravi, F.; Wiens, F.; DeCarli, A.; Pont, A.D.; Agostoni, C.; Ferraroni, M. Impact of maternal nutrition on breast-milk composition: A systematic review. Am. J. Clin. Nutr. 2016, 104, 646-662. [CrossRef] [PubMed]

5. Gidrewicz, D.A.; Fenton, T.R. A systematic review and meta-analysis of the nutrient content of preterm and term breast milk. BMC Pediatr. 2014, 14, 216. [CrossRef]

6. Innis, S.M. Impact of maternal diet on human milk composition and neurological development of infants. Am. J. Clin. Nutr. 2014, 99, 734S-741S. [CrossRef]

7. Kim, H.; Kang, S.; Jung, B.-M.; Yi, H.; Jung, J.A.; Chang, N. Breast milk fatty acid composition and fatty acid intake of lactating mothers in South Korea. Br. J. Nutr. 2017, 117, 556-561. [CrossRef]

8. Kelishadi, R.; Hadi, B.; Iranpour, R.; Khosravi-Darani, K.; Mirmoghtadaee, P.; Farajian, S.; Poursafa, P. A study on lipid content and fatty acid of breast milk and its association with mother's diet composition. J. Res. Med. Sci. 2012, 17, 824-827.

9. Tian, H.-M.; Wu, Y.-X.; Lin, Y.-Q.; Chen, X.-Y.; Yu, M.; Lu, T.; Xie, L. Dietary patterns affect maternal macronutrient intake levels and the fatty acid profile of breast milk in lactating Chinese mothers. Nutrients 2019, 58, 83-88. [CrossRef]

10. Whitfield, K.C.; Shahab-Ferdows, S.; Kroeun, H.; Sophonneary, P.; Green, T.J.; Allen, L.H.; Hampel, D. Macro- and Micronutrients in Milk from Healthy Cambodian Mothers: Status and Interrelations. J. Nutr. 2020, 150, 1461-1469. [CrossRef]

11. Muskiet, F.A.J.; Van Goor, S.A.; Kuipers, R.S.; Velzing-Aarts, F.V.; Smit, E.N.; Bouwstra, H.; Dijck-Brouwer, D.A.J.; Boersma, E.R.; Hadders-Algra, M. Long-chain polyunsaturated fatty acids in maternal and infant nutrition. Prostaglandins Leukot. Essent. Fat. Acids 2006, 75, 135-144. [CrossRef]

12. Institute for Public Health (IPH). National Institutes of Health. National Health and Morbidity Survey (NHMS) 2016: Maternal and Child Health; Ministry of Health: Kuala Lumpur, Malaysia, 2016; Volume 2.

13. Tan, S.S.; Khor, G.L.; Stoutjesdijk, E.; Ng, K.W.T.; Khouw, I.; Bragt, M.; Schaafsma, A.; Dijck-Brouwer, D.; Muskiet, F.A.J. Case study of temporal changes in maternal dietary intake and the association with breast milk mineral contents. J. Food Compos. Anal. 2020, 89, 103468. [CrossRef]

14. Ishak, S.; Adzan, N.A.M.; Quan, L.K.; Shafie, M.H.; Rani, N.A.; Ramli, K.G. Knowledge and Beliefs About Breastfeeding Are Not Determinants for Successful Breastfeeding. Breastfeed. Med. 2014, 9, 308-312. [CrossRef] [PubMed]

15. Fok, D.; Aris, I.M.; Ho, J.; Lim, S.B.; Chua, M.C.; Pang, W.W.; Saw, S.-M.; Kwek, K.; Godfrey, K.M.; Kramer, M.S.; et al. A Comparison of Practices During the Confinement Period among Chinese, Malay, and Indian Mothers in Singapore. Birth 2016, 43, 247-254. [CrossRef]

16. Yusoff, Z.M.; Amat, A.; Naim, D.; Othman, S. Postnatal Care Practices among the Malays, Chinese and Indians: A Comparison. In SHS Web Conference; EDP Sciences: Les Ulis, France, 2018; Volume 45, p. 05002. [CrossRef]

17. Paulaviciene, I.J.; Liubsys, A.; Molyte, A.; Eidukaite, A.; Usonis, V. Circadian changes in the composition of human milk macronutrients depending on pregnancy duration: A cross-sectional study. Int. Breastfeed. J. 2020, 15, 1-9. [CrossRef] [PubMed]

18. Muskiet, F.A.; Van Doormaal, J.J.; Martini, I.A.; Wolthers, B.G.; Van Der Slik, W. Capillary gas chromatographic profiling of total long-chain fatty acids cholesterol in biological materials. J. Chromatogr. B Biomed. Sci. Appl. 1983, 278, 231-244. [CrossRef]

19. Volmer, M.; Meiborg, G.; Muskiet, F.A. Simultaneous capillary gas chromatographic profiling of medium- and long-chain fatty acid methyl esters with split injection. J. Chromatogr. B Biomed. Sci. Appl. 1988, 434, 385-394. [CrossRef]

20. Li, C.; Solomons, N.W.; Scott, M.E.; Koski, K.G. Minerals and Trace Elements in Human Breast Milk Are Associated with Guatemalan Infant Anthropometric Outcomes within the First 6 Months. J. Nutr. 2016, 146, 2067-2074. [CrossRef] [PubMed]

21. Tee, E.S.; Mohd Ismail, N.; Mohd Nasir, A.; Khatijah, I. Nutrient Composition of Malaysian Foods, 4th ed.; Malaysian Food Composition Database Programmeme c/o Institute for Medical Research: Kuala Lumpur, Malaysia, 1997.

22. Agriculture Research Service. USDA Food Composition Databases; Nutrient Data Laboratory, Human Nutrition Research Center: Beltsville, MD, USA, 2016.

23. Foods Standards Australia New Zealand. Australia Food, Supplement and Nutrient Database (AUSNUT) 2011-2013; FSANZ: Canberra, Australia, 2015.

24. National Coordinating Committee on Food and Nutrition (NCCFN), Ministry of Health Malaysia. Recommended Nutrient Intakes for Malaysia 2017. Available online: nutrition.moh.gov.my/wp-content/uploads/2017/05/FA-Buku-RNI.pdf (accessed on 20 June 2020).

25. Chang, N.; A Jung, J.; Kim, H.; Jo, A.; Kang, S.; Lee, S.-W.; Yi, H.; Kim, J.; Yim, J.-G.; Jung, B.-M. Macronutrient composition of human milk from Korean mothers of full term infants born at 37-42 gestational weeks. Nutr. Res. Pract. 2015, 9, 433-438. [CrossRef]

26. Bzikowska-Jura, A.; Czerwonogrodzka-Senczyna, A.; Jasińska-Melon, E.; Mojska, H.; Oledzka, G.; Wesołowska, A.; SzostakWegierek, D. The Concentration of Omega-3 Fatty Acids in Human Milk Is Related to Their Habitual but Not Current Intake. Nutrients 2019, 11, 1585. [CrossRef]

27. Sambanthamurthi, R. Chemistry and biochemistry of palm oil. Prog. Lipid Res. 2000, 39, 507-558. [CrossRef]

28. Innis, S.M. Dietary omega 3 fatty acids and the developing brain. Brain Res. 2008, 1237, 35-43. [CrossRef] [PubMed]

29. Koletzko, B. Human Milk Lipids. Ann. Nutr. Metab. 2016, 69, 27-40. [CrossRef] [PubMed] 
30. Koletzko, B.; Thiel, I.; Abiodun, P.O. The fatty acid composition of human milk in Europe and Africa. J. Pediatr. 1992, 120, S62-S70. [CrossRef]

31. Yuhas, R.; Pramuk, K.; Lien, E.L. Human milk fatty acid composition from nine countries varies most in DHA. Lipids 2006, 41, 851-858. [CrossRef] [PubMed]

32. Floris, L.; Stahl, B.; Abrahamse-Berkeveld, M.; Teller, I. Human milk fatty acid profile across lactational stages after term and preterm delivery: A pooled data analysis. Prostaglandins Leukot. Essent. Fat. Acids 2020, 156, 102023. [CrossRef]

33. Innis, S.M. Palmitic Acid in Early Human Development. Crit. Rev. Food Sci. Nutr. 2016, 56, 1952-1959. [CrossRef]

34. Giuffrida, F.; Cruz-Hernandez, C.; Bertschy, E.; Fontannaz, P.; ElMelegy, I.M.; Tavazzi, I.; Marmet, C.; Sanchez-Bridge, B.; Thakkar, S.K.; De Castro, C.A.; et al. Temporal Changes of Human Breast Milk Lipids of Chinese Mothers. Nutrients 2016, 8, 715. [CrossRef]

35. Moossavi, S.; Atakora, F.; Miliku, K.; Sepehri, S.; Robertson, B.; Duan, Q.L.; Becker, A.B.; Mandhane, P.J.; Turvey, S.E.; Moraes, T.J.; et al. Integrated Analysis of Human Milk Microbiota with Oligosaccharides and Fatty Acids in the CHILD Cohort. Front. Nutr. 2019, 6, 58. [CrossRef]

36. Thakkar, S.K.; De Castro, C.A.; Beauport, L.; Tolsa, J.F.; Fumeaux, C.J.F.; Affolter, M.; Giuffrida, F. Temporal Progression of Fatty Acids in Preterm and Term Human Milk of Mothers from Switzerland. Nutrients 2019, 11, 112. [CrossRef]

37. Martin, M.; Lassek, W.D.; Gaulin, S.J.; Evans, R.W.; Woo, J.G.; Geraghty, S.R.; Davidson, B.S.; Morrow, A.L.; Kaplan, H.S.; Gurven, M.D. Fatty acid composition in the mature milk of Bolivian forager-horticulturalists: Controlled comparisons with a US sample. Matern. Child Nutr. 2012, 8, 404-418. [CrossRef]

38. German, J.B.; Dillard, C.J. Saturated Fats: A Perspective from Lactation and Milk Composition. Lipids 2010, 45, 915-923. [CrossRef]

39. Ooi, E.M.M.; Watts, G.F.; Ng, T.W.; Barrett, P.H.R. Effect of Dietary Fatty Acids on Human Lipoprotein Metabolism: A Comprehensive Update. Nutrients 2015, 7, 4416-4425. [CrossRef]

40. Ramiro-Cortijo, D.; Singh, P.; Liu, Y.; Medina-Morales, E.; Yakah, W.; Freedman, S.D.; Martin, C.R. Breast Milk Lipids and Fatty Acids in Regulating Neonatal Intestinal Development and Protecting against Intestinal Injury. Nutrients 2020, 12, 534. [CrossRef]

41. Leghi, E.G.; Middleton, P.F.; Netting, M.J.; Wlodek, E.M.; Geddes, D.T.; Muhlhausler, B.S. A Systematic Review of Collection and Analysis of Human Milk for Macronutrient Composition. J. Nutr. 2020, 150, 1652-1670. [CrossRef]

42. Fields, D.A.; Schneider, C.R.; Pavela, G. A narrative review of the associations between six bioactive components in breast milk and infant adiposity. Obesity 2016, 24, 1213-1221. [CrossRef] 